\title{
The Hajj: communicable and non-communicable health hazards and current guidance for pilgrims
}

Z A Memish (zmemish@yahoo.com)'

1. Ministry of Health, Riyadh, Saudi Arabia

Citation style for this article:

Memish ZA. The Haji: communicable and non-communicable health hazards and current guidance for pilgrims.

Euro Surveill. 2010;15(39):pii=19671. Available online: http://www.eurosurveillance.org/ViewArticle.aspx?Articleld=19671

Article published on 30 September 2010

The Hajj has become the epicenter of mass migration of millions of Muslims of enormous ethnic diversity. No other mass gathering can compare, either in scale or in regularity. Communicable disease outbreaks of various infectious diseases have been reported repeatedly, during and following the Hajj. The Hajj 2010 starts in the first week of November 2010 and this report is a timely reminder that many infectious diseases can be avoided or averted by adopting appropriate prophylactic measures.

\section{Introduction}

Hajj is the annual pilgrimage to Mecca in the Kingdom of Saudi Arabia (KSA). Every year the KSA hosts more than four million people from around 160 countries worldwide for both the Umra and Hajj season. From the European Union close to 45,000 pilgrims arrive to KSA each year. Hajj is thus one of the largest mass gatherings today (Table 1, Figure).

Extended stays at Hajj sites, physical exhaustion, extreme heat, and crowded accommodation encourage disease transmission, especially of airborne agents. Hajj-related transmission of infectious diseases and Hajj-related environmental and public health hazards are well described (Table 2) [1].

In 2009, Hajj was attended by over 2.5 million Muslims, of whom at least 1.6 million were foreign visitors. The vast majority ( $88 \%$ of all pilgrims) arrived by air (Figure 1) and although the Hajj ritual only takes one week many will gather for the month-long Hajj season.

\section{TABLE 1}

The number of pilgrims travelling to the Hajj, Saudi Arabia, 2006-2009 (1427-1430H)

\begin{tabular}{|l|c|}
\hline Year & Total number of international pilgrims \\
\hline $2006(1427 \mathrm{H})$ & $1,653,912$ \\
\hline $2007(1428 \mathrm{H})$ & $1,708,314$ \\
\hline $2008(1429 \mathrm{H})$ & $1,729,669$ \\
\hline $2009(1430 \mathrm{H})$ & $1,619,212$ \\
\hline
\end{tabular}

This event requires the planning and co-ordination of all government sectors of the KSA the whole year in advance. One of the major contributors to the planning and strategising for the well-being of the guests is the Ministry of Health $(\mathrm{MoH})$, whose Infection Control and Preventive Medicine Policies are established every year, based on knowledge of current global outbreaks, epidemiology of infectious diseases, and established effective preventive medicine strategies. Most recently, the KSA administered the 2009 Hajj amid a declared global $\mathrm{H}_{1} \mathrm{~N}_{1}$ pandemic. The Saudi response in preparing for and ensuring public health security for this mass gathering during such an unprecedented event has alerted international stakeholders to the complex implications and opportunities afforded by mass gatherings in advancing global health $[2,3,4]$.

\section{FIGURE}

Arrival of pilgrims according to ports of entry into Saudi Arabia in $2009(\mathrm{n}=1,619,212)$

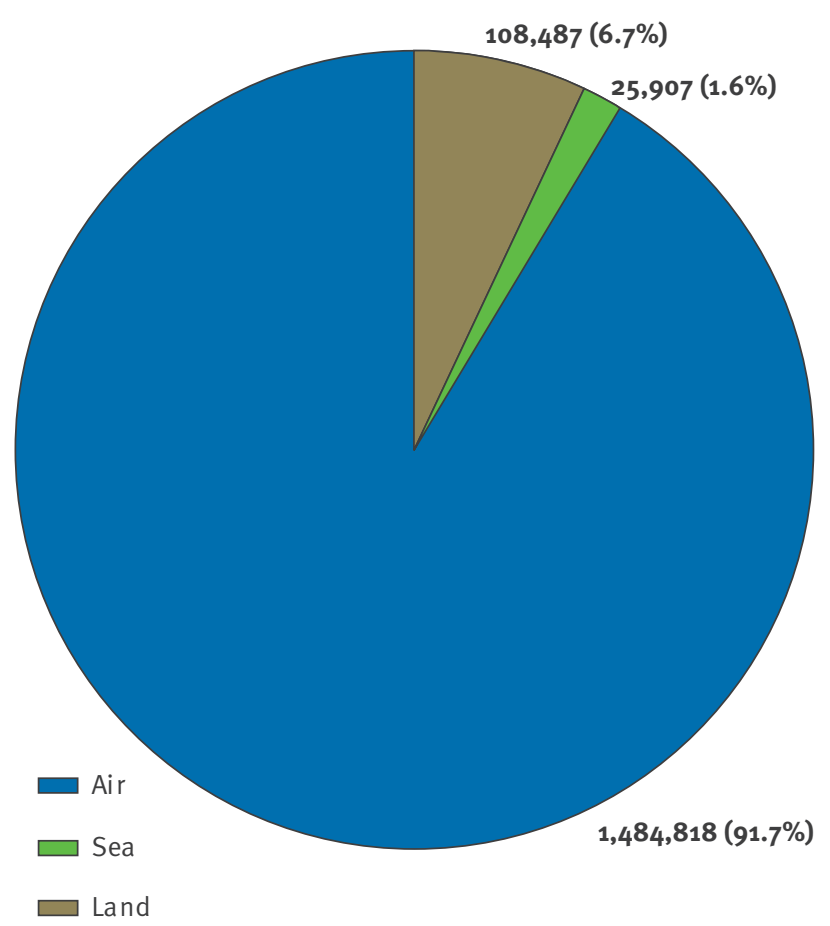


Preventive measures during

\section{Hajj in Saudi Arabia}

The KSA provides free healthcare to all pilgrims during the Hajj and also implements stringent infection control measures. In 2009, the KSA MoH prepared 24 hospitals with a total bed capacity of 4,964, of which 547 were critical care beds. Moreover 136 healthcare centers in the vicinity of the Hajj were equipped with the latest emergency management medical systems and staffed with 17,609 specialised personnel to provide state of the art healthcare to all pilgrims free of charge.

Along the pilgrimage route, the primary medical centers of the MoH, the Saudi National Guard, the Internal Security Forces and the Ministry of Defense and Aviation provide 24-hour free medical care.

Assisting in the Hajj planning and coordination are 24 supervisory committees reporting to the Minister of Health. The preventive medicine committee is one of the committees which oversee all key public health and preventative matters during the Hajj. The committee supervises a large number of public health officers who control the ports of entry for all pilgrims (land, sea and airports) and ensure compliance with Saudi $\mathrm{MoH}$ requirements for performing Hajj. In addition 39 public health teams are distributed around where the Hajj takes place. These include 18 stationary teams located in healthcare facilities and 21 mobile teams which rotate through the different pilgrim camps.

At the Hajj terminal based at King Abdulaziz International Airport in Jeddah, the key port of entry for the majority of pilgrims, an independent, newly renovated Hajj terminal now accommodates 80,000 pilgrims at any one time. At each of its 18 hubs receiving pilgrim flights there are two clinical examination rooms and a large holding area to assess arriving pilgrims and check their immunisation status and administer any recommended prophylactic medicines. Any pilgrim with a suspected communicable disease requiring isolation will be escorted back through the airport grounds by ambulance to a nearby dedicated 200 bed hospital.

The public health teams (stationary and mobile) as well as the ports of entry teams report directly to the command center on nine communicable diseases using an electronic surveillance form based on an updated disease case definition submitted via mobile phones. These diseases include influenza, influenza-like illness, meningococcal disease, food poisoning, viral hemorrhagic fevers, yellow fever, cholera, polio, and plague.

\section{Communicable disease at the Hajj}

\section{Meningococcal disease}

During the Hajj, carrier rates for meningococcal disease (MCD) rise to a level as high as $80 \%$ [5] due to intense overcrowding, high humidity and dense air pollution. When rates of carriage rise to this level, the risk for meningococcal outbreaks becomes a real concern. The largest meningococcal outbreak among pilgrims occurred in 1987 with meningococcal serogroup $A$ affecting pilgrims in Mecca and internationally [6]. Further to implementing vaccination with the bivalent $A$ and $C$ meningococcal vaccine as a requirement for attending the Hajj, no further outbreaks due to serogroup A occurred. In the years 2000 and 2001, two large outbreaks of meningococcal serogroup W135 occurred among pilgrims and their families in Saudi Arabia and internationally [7]. A change of the Haji pilgrimage requirements from bivalent to quadrivalent $(A, C, Y, W 135)$ meningococcal polysaccharide vaccine eliminated future meningococcal outbreaks [8]. Concerns still persist about hyporesponsiveness to the serogroup $\mathrm{C}$ component of the polysaccharide quadrivalent meningococcal vaccine despite repeat dosing [9]. Lack of herd immunity and persistence of meningococcal carriage among vaccinated pilgrims with the polysaccharide vaccine prompted the Saudi $\mathrm{MoH}$ to replace the local recommendations for meningococcal vaccination from polysaccharide to conjugated meningococcal vaccine [10]. Excessive cost of available conjugated meningococcal vaccines prohibited the $\mathrm{MoH}$ from mandating this recommendation to all international pilgrims.

\section{Respiratory tract infections}

Acute respiratory tract infections are very common during the Hajj, particularly so when the pilgrimage falls in the winter season. The close contact among pilgrims during periods of intense congestion, their shared

TABLE 2

Communicable and non-communicable diseases hazards at the Hajj

\begin{tabular}{|l|l|}
\hline \multicolumn{1}{|c|}{ Communicable hazards } & \multicolumn{1}{c|}{ Non-communicable hazards } \\
\hline Meningococcal meningitis & Trauma e.g. stampede and motor vehicle accident \\
\hline $\begin{array}{l}\text { Respiratory tract infections (upper and lower) including tuberculosis, viral infections and } \\
\text { community-acquired pneumonia }\end{array}$ & Slaughter related injuries \\
\hline Polio virus & Heat stroke and heat exhaustion \\
\hline Blood-borne diseases & Sunburn \\
\hline Food poisoning & Dehydration \\
\hline Zoonotic diseases & Fire related injuries \\
\hline
\end{tabular}


sleeping accommodations (mainly in tents) and the dense air pollution all combine to increase the risk of airborne respiratory disease transmission. A viral etiology of upper respiratory tract infection (URTI) is most commonly implicated at the Hajj but bacterial superinfection often follows. More than 200 viruses can cause URTI but at the Hajj the main culprits are respiratory syncytial virus (RSV), parainfluenza, influenza and adenovirus [11].

The intense congestion, living in close proximity with vast crowds and the increasing percentage of elderly pilgrims, are all factors magnifying tuberculosis (TB) risk. Additionally many Muslims travel from countries of high TB endemicity. The exact risk of TB transmission among pilgrims is difficult to quantify. A study among 357 Singaporean pilgrims revealed that $10 \%$ showed a substantial rise in immune response to the QuantiFERON TB assay antigens post-Hajj when compared to a pre-Hajj test [12].

Pertussis is another respiratory tract infection of concern during Hajj. One study found a high incidence of pertussis in Hajj pilgrims with an overall incidence of pertussis (1.4\%) during this one month long pilgrimage [13] Hajj pilgrims would therefore benefit from pertussis vaccination prior to their departure.

In an attempt to reduce the risk of respiratory tract infections during the Hajj, the Saudi $\mathrm{MoH}$ encourages pilgrims to wear surgical face mask when in crowded places. In addition the $\mathrm{MoH}$ recommends that international pilgrims be vaccinated against seasonal influenza before arrival into the kingdom of Saudi Arabia with World Health Organization approved strains specific to the northern or southern hemispheres, particularly those with pre-existing conditions (e.g. the elderly, people with chronic chest or cardiac, hepatic or renal disease). In KSA seasonal influenza vaccine is recommended for internal pilgrims particularly those with pre-existing conditions and all healthcare workers working in the Hajj premises.

\section{Blood-borne diseases}

Muslim men observe completion of a successful Hajj by shaving their heads. Head shaving is an important means of transmission of blood-borne disease, including hepatitis B, C and HIV. Illegal unlicensed barbers continue to operate at the Hajj, shaving hair at the roadside with non-sterile blades, which are re-used on multiple scalps. The Saudi MoH encourages all pilgrims to receive the full series of hepatitis $B$ vaccination prior to travel to Hajj [1] As well all pilgrims should avoid unlicensed barbers and seek approved licensed barber facilities at the Hajj premises to shave their heads [1].

\section{Diarrhoea and food poisoning}

Traveller's diarrhoea is common during the Hajj, although few studies have documented its incidence and etiology. The last study was done in 2002 showing that diarrhoea was the third most common cause for hospitalisation during Hajj. Cholera, an acute bacterial enteric disease caused by Vibrio cholerae accounted for several outbreaks after the Hajj $[14,15]$. The last reported by the $\mathrm{MoH}$ was in 1989 affecting 102 pilgrims. Significant improvement in water supply and sewage treatment has eliminated such outbreaks. Concerns still persist about importing cholera with pilgrims from affected countries which will cause widespread outbreaks in Mecca. The MoH has strict guidelines on food importation by pilgrims. Food carried by visitors and pilgrims is banned and not allowed into the country. Only properly canned foods and in very small amounts, enough for one person for the duration of the visit are allowed.

Poliomyelitis is an acute viral infection that is acquired by fecal-oral or oral transmission. International spread of polio through pilgrimage is a major concern for Saudi Arabia. Only four countries (Afghanistan, India, Nigeria and Pakistan) have never completely interrupted the transmission of wild polio virus. All pilgrims from these four countries, regardless of age and vaccination status, should receive one dose of oral polio vaccine (OPV). Proof of OPV vaccination at least six weeks prior departure is required to apply for an entry visa for Saudi Arabia. These travellers will also receive a dose of OPV at border points when arriving in Saudi Arabia. All visitors age under the age of 15 travelling to Saudi Arabia from countries reinfected with poliomyelitis should be vaccinated against poliomyelitis with OPV. Proof of OPV vaccination is required six weeks prior to the application for an entry visa. Irrespective of previous immunization history, all visitors under 15 years arriving in Saudi Arabia will also receive a dose of OPV at border points.

\section{Non-communicable hazards at the Hajj}

When Hajj falls during the summertime temperatures in the Hajj premises may reach from 37 to $45^{\circ} \mathrm{C}$. Heat exhaustion and heat stroke could become a major cause of morbidity and mortality in pilgrims if appropriate precautions are not taken such as reducing their level of activity, drinking additional water, consume salty food and increase the amount of time they spend in air conditioned environment [16]. Other hazards include trauma/crush injuries and fire related injuries

\section{Pre- and post-Hajj travel advice}

Hajj presents a unique challenge that impacts the international public health as an increasing number of humans become more mobile. Clinicians everywhere must be aware of potential risks disease transmission and suggest appropriate strategies, which can be applied before departure and implemented in the field. Practitioners must also be aware of the risks presented by the returned pilgrim, and be alert to diagnose postHajj illness.

Increasingly, international collaboration (in planning vaccination campaigns, developing visa quotas, arranging rapid repatriation, managing health hazards 
at the Hajj and providing care beyond the holy sites) has become essential. Planning and supporting Hajj has become a forum for collaboration crossing any political considerations. The Saudi $\mathrm{MoH}$ every year publishes the Hajj requirements for the upcoming Hajj season which is a good guide to all needed precautions to ensure safe Hajj for all pilgrims. This year Hajj recommendations were published in the Journal of Infection and Public Health [17] and will be published the WHO WER issue No.43, Volume 85, scheduled for release 22 October 2010.

\section{References}

1. Ahmed Q, Arabi Y, Memish ZA. Health risks at the Hajj. Lancet 2006;367(9515):1008-15

2. Khan K, Memish Z, Chabbra A, Liauw J, Hu W, Janes DA, et al. Global public health implications of a mass gathering in Mecca, Saudi Arabia during the midst of an influenza pandemic. J Travel Med. 2010;17(2):75-81

3. No authors listed]. Editorial. Lessons from a pandemic. Nature 2010: 463(7278):135-6

4. Ebrahim SH, Memish ZA, Ueyki TM, McNabb SJ. Pandemic $\mathrm{H}_{1} \mathrm{~N}_{1}$ and the 2009 Hajj. Science. 2009;326(5955):938-40

5. al-Gahtani YM, el Bushra HE, al-Qarawi SM, al-Zubaidi AA, Fontaine RE. Epidemiolological investigation of an outbreak of meningococcal meningitis in makkah (Mecca), Saudi Arabia, 1992. Epidemiol Infect. 1995;115(3): 399-409

6. Moore PS, Reeves MW, Schwartz B, Gellin BG, Broome CV. Intercontinental spread of an epidemic group A Neisseria meningitides strain. Lancet. 1989; 2(8657):260-3.

7. Memish ZA, Venkatesh S, Ahmed QA. Travel epidemiology: the Saudi perspective. Int J Antimicrob Agents. 2003; 21(2): 96-101

8. Borrow R.Meningococcal disease and prevention at the Hajj. Travel Med Infect Dis. 2009(4):219-25

9. Jokhdar H, Borrow R, Sultan A, Adi M, Riley C, Fuller E, et al. Immunologic hyporesponsiveness to serogroup $C$ but not serogroup $A$ following repeated meningococcal $A / C$ polysaccharide vaccination in Saudi Arabia. Clin Diagn Lab Immunol. 2004;11(1):83-8.

10. Memish ZA, Goubeaud A, Bröker M, Malerczyk C, Shibl AM Invasive meningococcal disease and travel. J Infect Public Health. 2010 (in press)

11. Balkhy HH, Memish ZA, Bafaqeer S, Almuneef MA. Influenza a common viral infection among Hajj pilgrims: time for routine surveillance and vaccination. J Travel Med. 2004;11(2):82-6

12. Wilder-Smith A, Foo W, Earnest A, Paton NI. High risk of Mycobacterium tuberculosis infection during the $\mathrm{Hajj}$ pilgrimage. Trop Med Int Health. 2005;10(4):336-9

13. Wilder-Smith A, Earnest A, Ravindran S, Paton NI. High incidence of pertussis among Hajj pilgrims. Clin Infect Dis. 2003;37(9):1270-72

14. Onishchenko GG, Lomov lu M, Moskvitina EA. [Cholera in the Republic of Dagestan]. Zh Mikrobiol Epidemiol Immunobiol. 1995;Suppl 2:3-8. Russian

15. Onishchenko GG, Lomov luM, Moskvitina EA et al. [The epidemiological characteristics of cholera in the Republic of Dagestan. An assessment of the epidemic-control measures]. Zh Mikrobiol Epidemiol Immunobiol. 1995;Suppl2:9-22. Russian.

16. Bouchama A, Knochel JP. Heat stroke. N Engl J Med. 2002;346(25):1978-88

17. Memish ZA. Health conditions for travelers to Saudi Arabia for (Hajj) for the year $1431 \mathrm{H} / 2010$. J Infect Public Health 2010;3:92-4 